
3 Research Square
Preprints are preliminary reports that have not undergone peer review.
They should not be considered conclusive, used to inform clinical practice,
or referenced by the media as validated information.

\title{
The Gardening Activities to Reduce Postpartum Stress in Japanese Postpartum Women: Preliminary Evidence from Pilot Single-Arm Trial Study
}

Yuka Kotozaki ( $\sim$ kotoyuka@iwate-med.ac.jp )

\section{Research note}

Keywords: postpartum women, postpartum stress, parenting stress, gardening activity, mental health, stress, quality of life

Posted Date: May 29th, 2020

DOl: https://doi.org/10.21203/rs.3.rs-29706/v1

License: () (1) This work is licensed under a Creative Commons Attribution 4.0 International License. Read Full License 


\section{Abstract \\ Objective}

There is a need for safer and more effective programs to address postpartum women's mental health dysfunction. The objective of this study was to clarify the effects on mental health, including postpartum depression, by implementing Japanese postpartum women with gardening activities by a pilot single-arm trial.

\section{Results}

15 women about a year after giving birth, recruited through newspaper advertisements, took part in this pilot study. I used the Japanese version of Edinburgh Postpartum Depression Scale (EPDS) score as the primary outcome measure. Secondary outcome measures were parenting stress, anxiety, and quality of life (QOL). Data collected at pre and post-test were analyzed using a paired t test. The EPDS, stress regarding parents, State-Trait Anxiety Inventory (STAI)-state, and STAI-trait of post-test were significant decreased than pre-test $(p<0.05)$. Also, physical health and psychological health of the World Health Organization Quality of life 26 (WHOQOL-26) of post-test were significantly increased than pre-test $(p<0.05)$. The gardening activity might be promising for mitigating depressive mood in postpartum women.

\section{Introduction}

Women are more likely to have depression during pregnancy and after childbirth (Evans, Heron, Francomb, Oke, \& Golding, 2001; Gavin et al., 2005; Pitt, 1968; Söderquist, Wijma, Thorbert, \& Wijma, 2009; Zaers, Waschke, \& Ehlert, 2008). 19.2\% have postnatal depression worldwide (Gavin et al., 2005). Postpartum depression may be developed even for women without history of stress illness or in women who have not seen depression during first pregnancy and childbirth (Biaggi, Conroy, Pawlby, \& Pariante, 2016; "Postnatal depression-NHS," 2018; Smith, Shao, Howell, Lin, \& Yonkers, 2011). However, many women who have depression after giving birth, however, do not have sufficient support and appropriate treatment around them, often hesitate to consult a specialist due to the difficulty of going to the hospital with an infant or having trouble with medication while breastfeeding (Bilszta et al., 2010). A neglecting postpartum depression might cause a greater risk of severe and chronic disease and have more impact on children (Brennan et al., 2000; Dunkel Schetter \& Tanner, 2012; Glover, 2014, 2015; Orsolini et al., 2016), so early and less burdensome measures for mothers who have just given birth is necessary. Therefore, it focused on gardening activities.

The horticultural therapy is a process through which plants, gardening activities, and an innate closeness to nature are used in therapy programs (HAYASH et al., 2008). The gardening activity is based not only on the effects of a series of gardening activities of growing, harvesting and incorporating them into life, but also on the effect of the physical function being restored as well as the attachment to the plants (Gonzalez, Hartig, Patil, Martinsen, \& Kirkevold, 2010; HansenKetchum, Marck, \& Reutter, 2009; HAYASHI et al., 2008; Maller, Townsend, Pryor, Brown, \& Leger, 2006; Page, 2008). The gardening activity is thought to have psychological improvement effects such as gaining self-confidence, sense of achievement, satisfaction, joy, and happiness, as well as relieving stress (Sempik, J; Aldridgem, J; Becker, 2003; Unruh, 2004) and increasing imagination and memory. However, there are few studies on those of postpartum depression due to life intervention, and their effects are unclear. This study aimed to clarify the effects on mental health, including postpartum depression, by implementing postpartum women in Japan with gardening activities by a pilot single-arm trial.

\section{Materials And Methods}

\section{Study design}

This study was a prospective clinical pilot study of a single-group open-label trial. The Research Ethics Committee of Iwate Medical University approved all procedures (MH2018-512). This study was registered in the national UMIN Clinical Trials Registry (ID: UMIN000034331). Written informed consent was obtained from all participants. All procedures were performed in accordance with the Helsinki Declaration. We estimated that a sample size of 15 would allow us to detect significant differences in the cognitive score before and after gardening activity with $80 \%$ power $(a=0.05)$ by previous studies (Alston, 2010) (Gigliotti, Jarrott, \& Yorgason, 2004) and we determined our sample size to be 15.

\section{Study subjects}

We recruited 15 women (mean age: $30.4 \pm 3.2$ years old) of about one year after chirdbirth recruited by newspaper advertisement. The consolidated standards of reporting trial (CONSORT) flowchart is provided in Figure 1.

\section{Overview of Interventions}

This intervention included easy gardening activities. The activities were not part of the ordinary farm work. Full details of the gardening activities have been provided in a previous publication (Kotozaki, 2014). Participants were asked to attend in a total of eight gardening activities once a week. Gardening activities for 1 hour, once a week for 8 consecutive weeks on weekday at the lecture room of Iwate Medical University. Psychological measurements were taken before the start and after the end of the program. Participants completed a series of psychological tests before beginning the program schedule (Pre-test). After 8 weeks, participants were re-examined using the same psychological tests (Post-test).

\section{Assessment of Postpartum Depression}


Postpartum depression was screened using the Japanese version of Edinburgh Postpartum Depression Scale (EPDS) (Okano T MM, Masuji F, Tamaki R, Nomura J, 1996). The EPDS is commonly used to screen for symptoms of depression, including anxiety, feelings of guilt, and dysphoria, during and after pregnancy. The ten-item self-reported questionnaire assesses the frequency of depressive symptoms over the preceding seven days and scored using a fourpoint scale ( $0-3)$. A higher score indicates a higher degree of depressive symptoms. As recommended by the instrument authors, a score of thirteen or more was regarded as 'probable depression' and a score of ten to twelve suggests 'possible depression'.

\section{Assessment of Parenting Stress}

Parenting stress was screened using the Japanese version of Parenting Stress Index (PSI) (Narama M, Kanematsu Y, Araki A, Maru M, Nakamura N, 1999). The PSI includes 78 items, which are classified into 7 subscales for the stress regarding children (PSIc) and 8 subscales for the stress regarding parents (PSIp). It is scored on a 5-point scale and a higher score means a high level of parenting stress.

\section{Other psychological measurements}

Anxiety was screened using the Japanese version of State-Trait Anxiety Inventory (STAI) (Nakazato, K., Mizuguchi, 1982). The STAI measures state anxiety and trait anxiety separately. Both the state and trait sections of this questionnaire comprise 20 questions, with total scores on each section ranging from 20 to 80. STAl-state scores of $\geq 51$ and STAI-trait scores of $\geq 55$ suggest diagnoses of anxiety disorder and pathological vulnerability to threat as a personality trait. Quality of life was measured using the Japanese version of World Health Organization Quality of life 26 (WHOQOL-26) (Tazaki, M; Nakane, 1997). The WHOQOL-26 is a 26 -item self-report questionnaire. It is scored on a 5-point scale, with higher scores indicating better QOL. The 26 items are classified into four domains: physical health, psychological health, social relationship and environment.

\section{Demographic characteristics}

Participants also answered their age, the educational background, marital status, current smoking and alcohol drinking habits. The educational level (high school/college/university or more) were obtained via the questionnaire using the question "What is your last educational background?" Marital status (single/married/divorce) were obtained via the questionnaire using the question "Are you currently married?" Current smoking and alcohol drinking habits (yes/no) were obtained via the questionnaire using the question "Are you a habitual smoker/drinker?"

\section{Statistical analyses}

Descriptive statistics was reported (means and standard deviations (SD)). Differences in outcome variables (pre and post-test) were analyzed using a paired $t$ test. Data was analyzed using IBM SPSS Statistics version 25.0 (SPSS, Chicago, IL, USA), and the significance level was set at $\mathrm{p}<0.05$.

\section{Results}

The characteristics of the study subjects are listed in Table 1. The mean age was 30.4 years old $(S D= \pm 3.2)$. All subjects had completed their education at the high school level and more. Over $80 \%$ of the subjects were married. There were no smokers. $20 \%$ of the subjects were drinking.

The comparison of pre and post-test scores are showed in Table 2. The EPDS, PSIp, STAI-state, and STAl-trait of post-test were significant decreased than pretest $(p<0.05)$. Also, physical health and psychological health of the WHOQOL-26 of post-test were significantly increased than pre-test $(p<0.05)$.

\section{Discussion}

The aim of this study was to clarify the effects of mothers on mental health, including postpartum depression, by implementing Japanese postpartum women with gardening activities. In the present study, postpartum depression, the stress regarding parents, and anxiety of post-test were significantly decreased compared with pre-test. The physical health domain and psychological health domain of the QOL of post-test were significantly increased compared with pretest. This is the first report of examined the effects of gardening activities on mental health of Japanese postpartum women.

Regarding postpartum depression and gardening activity, the present study showed postpartum stress was reduced after gardening activity. Previously, the direct relationship between gardening activity and postnatal depression was not known. In Regarding the difference between the previous study and the present study, the previous studies investigated the relationship between postnatal depression and physical activity including other activities such as exercise, as well as gardening activity (Demissie et al., 2011; Saligheh, Rooney, McNamara, \& Kane, 2014). A prospective study of mothers followed through 12 months postpartum (Demissie et al., 2011) and a questionnaire survey of 150 postpartum women (Saligheh et al., 2014) reported that there was no association between recreational and outdoor household moderate to vigorous physical activity including gardening and depressive symptoms. Focusing on stress and gardening activity, the previous studies showed that in the gardening activity effective in reducing stress (Francis \& Hester, 1992; Gross \& Lane, 2007; HAYASHI et al., 2008; Milligan, Gatrell, \& Bingley, 2004). Also, the gardening has been found to have positive health effects on people with stress-related ill health (Eriksson T, Karlström E, Jonsson H, 2010). Many of the reasons for gardening are relaxation and stress reduction (Armstrong, 2000; Clayton, 2007; Dunnett \& Qasim, 2000). The gardening has become recognized as an activity that provides effective relief from stress and mental fatigue (Kaplan \& Kaplan, 1989). Other studies have shown that gardening is related to lower likelihood of depression (Teychenne, Ball, \& Salmon, 2008). Based on the above, it has already been reported that gardening on a regular basis is also effective in reducing stress, and it may be possible to say that it has a similar effect on postpartum depression.

As for parental stress and gardening activity, the present study showed parental stress was reduced after gardening activity. In the previous study, parents who have children attending primary school reported the plant cultivation activity program can boost parental stress-reducing effects, and provide positive 
influence on relieving parenting stress (Jang, Gim, Jeong, \& Kim, 2018). Also, it reported that parents of elementary school students experienced that their depression and stress were relieved through plant cultivating activity (Hwang, HyunJung ; Lee, YoungAe ; Song, JongEun ; Son, 2007). Although the age group of children in the previous study and the current study differed, the stress felt during child-rearing was considered to be common, and the similar results of reducing stress through horticultural activity may reinforce the possibility that horticultural activity are effective in reducing stress among parents.

The present study showed a decrease in anxiety after horticultural activity. This result is consistent with previous studies (Gonzalez et al., 2010; Gonzalez, Hartig, Patil, Martinsen, \& Kirkevold, 2011a; Kam \& Siu, 2010). The attended 10 horticultural sessions within 2 week was a significant difference in change scores of anxiety (Kam \& Siu, 2010). A 12-week gardening activity with people with depression also improved anxiety scores (Gonzalez et al., 2010; Gonzalez, Hartig, Patil, Martinsen, \& Kirkevold, 2011b). Despite the differences in the duration of the interventions in both the present and previous studies, the anxiety was reduced after the horticultural activity, and it can be said that the effects of the horticultural activity are recognized.

As for the QOL, the present study was improved the physical health domain and the psychological health domain of the QOL after gardening activity. It has been suggested that horticultural activities have the potential to improve the QOL (Aime J. Sommerfeld, Tina M. Waliczek, 2010; Biddle, S. H. J., Ekkekakis, 2005; WaliczekT.M.MattsonR.H.ZajicekJ.M., 1996). Although many previous studies have targeted middle-aged and older people, the fact that similar results were found in young people, the subject of this study, suggests once again that horticultural activities may improve quality of life regardless of age.

\section{Conclusion}

This study found postpartum depression, parental stress, anxiety, and the QOL of Japanese postpartum women were improved by gardening activities. The gardening activity might be promising for mitigating depressive mood in postpartum women.

\section{Limitations}

This study was a single-arm study, it is susceptible to the influence of confounding factors for not providing the control condition. Second, alongside with revision of the program, future randomized controlled trials are required to validate the effectiveness of the program.

\section{Abbreviations}

\section{QOL}

Quality of life

UNIM

University Hospital Medical Information Network

CONSORT

Consolidated standards of reporting trial

EPDS

Edinburgh Postpartum Depression Scale

PSI

Parenting Stress Index

PSIC

Stress regarding children

PSIp

Stress regarding parents

STAI

State-Trait Anxiety Inventory

WHOQOL-26

World Health Organization Quality of life 26

SD

Standard deviations

\section{Declarations}

\section{Authors' contributions}

YK wrote the draft of this manuscript, contributed to the conception and design of this study, and critically reviewed the manuscript and supervised the whole study process. All authors read and approved the final manuscript.

\section{Acknowledgements}

The author appreciate women who participated in the study. I deeply thank Mrs. Teruko Tachibana and Mrs. Yoshiko Sasaki for study assistant. The funders had no role in study design and analysis or preparation of the manuscript.

Ethics approval and consent to participate 
All procedures were performed in accordance with the Helsinki Declaration. This study was approved by the Research Ethics Committee of Iwate Medical University approved all procedures (MH2018-512). This study was registered in the national UMIN Clinical Trials Registry (ID: UMIN000034331). Written informed consent was obtained from all participants.

\section{Funding}

This work was supported by the grants from Scholarship Fund for Women Researchers.

\section{Competing interests}

The authors declare that they have no competing interests.

\section{Availability of data and materials}

The datasets analyzed during the current study are available from the corresponding author on reasonable request.

\section{Consent to publish}

Not applicable.

\section{References}

Aime J. Sommerfeld, Tina M. Waliczek, J. M. Z. (2010). Growing Minds: Evaluating the Effect of Gardening on Quality of Life and Physical Activity Level of Older Adults. HortTechnology, 20(4), 705-710.

Alston, L. Y. (2010). Digital Commons @Brockport The Effectiveness of Horticultural Therapy Groups on Adults with a Diagnosis of Depression The Effectiveness of Horticultural Therapy Groups on Adults with a Diagnosis of Depression THE EFFECTIVENESS OF A HORTICULTURAL THERAPY G. Retrieved from http://digitalcommons.brockport.edu/edc_theses/1

Armstrong, D. (2000). A survey of community gardens in upstate New York: Implications for health promotion and community development. Health and Place, 6(4), 319-327. https://doi.org/10.1016/S1353-8292(00)00013-7

Biaggi, A., Conroy, S., Pawlby, S., \& Pariante, C. M. (2016, February 1). Identifying the women at risk of antenatal anxiety and depression: A systematic review. Journal of Affective Disorders, Vol. 191, pp. 62-77. https://doi.org/10.1016/j.jad.2015.11.014

Biddle, S. H. J., Ekkekakis, P. (2005). Physical active lifestyles and well-being. (\& B. K. F. A. Huppert, N. Baylis, Ed.). Retrieved from https://books.google.co.jp/books?

$\mathrm{hl}=$ ja\&lr=lang_ja\%7Clang_en\&id=DDFqqeko9boC\&oi=fnd\&pg=PA141\&ots=VqkUWxR3h6\&sig=Ba8w06IUwlpAjBUMlonllpVjzo4\&redir_esc=y\#v=onepage\&q\&f=f

Bilszta, J., Ericksen MPsych, J., Buist MBBS, A., of Women, P., Health, M., Health, A., \& Milgrom, J. (2010). Women's experience of postnatal depression beliefs and attitudes as barriers to care. AUSTRALIAN JOURNAL OF ADVANCED NURSING, 27(3).

Brennan, P. A., Hammen, C., Andersen, M. J., Bor, W., Najman, J. M., \& Williams, G. M. (2000). Chronicity, Severity, and Timing of Maternal Depressive Symptoms: Relationships With Child Outcomes at Age 5. Developmental Psychology. https://doi.org/10.1037/0012-1649.36.6.759

Clayton, S. (2007). Domesticated nature: Motivations for gardening and perceptions of environmental impact. Journal of Environmental Psychology, 27(3), 215-224. https://doi.org/10.1016/j.jenvp.2007.06.001

Demissie, Z., Siega-Riz, A. M., Evenson, K. R., Herring, A. H., Dole, N., \& Gaynes, B. N. (2011). Associations between physical activity and postpartum depressive symptoms. Journal of Women's Health, 20(7), 1025-1034. https://doi.org/10.1089/jwh.2010.2091

Dunkel Schetter, C., \& Tanner, L. (2012, March). Anxiety, depression and stress in pregnancy: Implications for mothers, children, research, and practice. Current Opinion in Psychiatry, Vol. 25, pp. 141-148. https://doi.org/10.1097/YC0.0b013e3283503680

Dunnett, N., \& Qasim, M. (2000). Perceived Benefits to Human Well-being of Urban Gardens.

Eriksson T, Karlström E, Jonsson H, T. K. (2010). An exploratory study of the rehabilitation process of people with stress-related disorders. Scand J Occup Ther., $17(1), 29-39$.

Evans, J., Heron, J., Francomb, H., Oke, S., \& Golding, J. (2001). Cohort study of depressed mood during pregnancy and after childbirth. British Medical Journal, 323(7307), 257-260. https://doi.org/10.1136/bmj.323.7307.257

Francis, M., \& Hester, R. T. (1992). The meaning of gardens : idea, place, and action.

Gavin, N. I., Gaynes, B. N., Lohr, K. N., Meltzer-Brody, S., Gartlehner, G., \& Swinson, T. (2005). Perinatal depression: A systematic review of prevalence and incidence. Obstetrics and Gynecology, Vol. 106, pp. 1071-1083. https://doi.org/10.1097/01.AOG.0000183597.31630.db 
Gigliotti, C. M., Jarrott, S. E., \& Yorgason, J. (2004). Harvesting Health: Effects of Three Types of Horticultural Therapy Activities for Persons with Dementia. Dementia, 3(2), 161-180. https://doi.org/10.1177/1471301204042335

Glover, V. (2014). Maternal depression, anxiety and stress during pregnancy and child outcome; What needs to be done. Best Practice and Research: Clinical Obstetrics and Gynaecology, 28(1), 25-35. https://doi.org/10.1016/j.bpobgyn.2013.08.017

Glover, V. (2015). Prenatal stress and its effects on the fetus and the child: Possible Underlying biological mechanisms. In Advances in Neurobiology (Vol. 10, pp. 269-283). https://doi.org/10.1007/978-1-4939-1372-5_13

Gonzalez, M. T., Hartig, T., Patil, G. G., Martinsen, E. W., \& Kirkevold, M. (2010). Therapeutic horticulture in clinical depression: a prospective study of active components. Journal of Advanced Nursing, 66(9), no-no. https://doi.org/10.1111/j.1365-2648.2010.05383.x

Gonzalez, M. T., Hartig, T., Patil, G. G., Martinsen, E. W., \& Kirkevold, M. (2011a). A prospective study of existential issues in therapeutic horticulture for clinical depression. Issues in Mental Health Nursing, 32(1), 73-81. https://doi.org/10.3109/01612840.2010.528168

Gonzalez, M. T., Hartig, T., Patil, G. G., Martinsen, E. W., \& Kirkevold, M. (2011b). A prospective study of group cohesiveness in therapeutic horticulture for clinical depression. International Journal of Mental Health Nursing, 20(2), 119-129. https://doi.org/10.1111/j.1447-0349.2010.00689.x

Gross, H., \& Lane, N. (2007). Landscapes of the lifespan: Exploring accounts of own gardens and gardening. Journal of Environmental Psychology, 27(3), 225-241. https://doi.org/10.1016/j.jenvp.2007.04.003

Hansen-Ketchum, P., Marck, P., \& Reutter, L. (2009). Engaging with nature to promote health: new directions for nursing research. Journal of Advanced Nursing, 65(7), 1527-1538. https://doi.org/10.1111/j.1365-2648.2009.04989.x

HAYASHI, N., WADA, T., HIRAI, H., MIYAKE, T., MATSUURA, Y., SHIMIZU, N., ... HORIUCHI, S. (2008). The Effects of Horticultural Activity in a Community Garden on Mood Changes. Environment Control in Biology, 46(4), 233-240. https://doi.org/10.2525/ecb.46.233

Hwang, HyunJung ; Lee, YoungAe ; Song, JongEun ; Son, K. (2007). Effect of horticultural therapy based upon reality therapy on the reduction of depression, the change in parental sense of competence, and stress coping types of elementary student's mother. Korean Journal of Horticultural Science \& Technology, 25(3), 268-276.

Jang, H. S., Gim, G. M., Jeong, S.-J., \& Kim, J. S. (2018). Effects of Plant Cultivating Activity for Reducing Parental Stress. Journal of People, Plants, and Environment, 21(3), 203-211. https://doi.org/10.11628/ksppe.2018.21.3.203

Kam, M. C. Y., \& Siu, A. M. H. (2010). Evaluation of a horticultural activity programme for persons with psychiatric illness. Hong Kong Journal of Occupational Therapy, 20(2), 80-86. https://doi.org/10.1016/S1569-1861(11)70007-9

Kaplan, R., \& Kaplan, S. (1989). The Experience of Nature A Psychological Perspective The right of the CAMBRIDGE UNIVERSITY PRESS Cambridge New York Port Chester Melbourne Sydney.

Kotozaki, Y. (2014). Horticultural therapy as a measure for recovery support of regional community in the disaster area: a preliminary experiment for forty five women who living certain region in the coastal area of Miyagi Prefecture. I Semantic Scholar. Retrieved April 15, 2020, from https://www.semanticscholar.org/paper/Horticultural-therapy-as-a-measure-for-recovery-of-Kotozaki/19501f76e323519a78a343856fc6bd64b696f66d

Maller, C., Townsend, M., Pryor, A., Brown, P., \& Leger, L. S. (2006). Healthy nature healthy people: "contact with nature" as an upstream health promotion intervention for populations. Health Promotion International, 21(1). https://doi.org/10.1093/heapro/dai032

Milligan, C., Gatrell, A., \& Bingley, A. (2004). "Cultivating health”: Therapeutic landscapes and older people in northern England. Social Science and Medicine, 58(9), 1781-1793. https://doi.org/10.1016/S0277-9536(03)00397-6

Nakazato, K., Mizuguchi, T. (1982). Development and validation of Japanese version of State-Trait Anxiety Inventory-A study with female subjects. Jpn J Psychosom Med, 22, 107-112. Retrieved from http://ci.nii.ac.jp/naid/10016046307/en/

Narama M, Kanematsu Y, Araki A, Maru M, Nakamura N, et al. (1999). Nihonban parenting stress index (PSI) no shinraisei, datousei no kentou [Review of reliability and validity of Japanese version of parenting stress index (PSI)]. Shoni Hoken Kenkyu, 58(5), 610-616. Retrieved from http://ci.nii.ac.jp/naid/10029703225/ja/

Okano T MM, Masuji F, Tamaki R, Nomura J, M. H. (1996). Validation and reliability of a Japanese version of the EPDS. Archives of Psychiatric Diagnosis and Clinical Evaluation, 7, 525-533. Retrieved from http://ci.nii.ac.jp/naid/10029703310/ja/

Orsolini, L., Valchera, A., Vecchiotti, R., Tomasetti, C., lasevoli, F., Fornaro, M., ... Bellantuono, C. (2016, August 12). Suicide during perinatal period: Epidemiology, risk factors, and clinical correlates. Frontiers in Psychiatry, Vol. 7. https://doi.org/10.3389/fpsyt.2016.00138

Page, M. (2008). Gardening as a therapeutic intervention in mental health. Nursing Times, 104(45), 28-30.

Pitt, B. (1968). "Atypical" depression following childbirth. The British Journal of Psychiatry: The Journal of Mental Science, 114(516), 1325-1335.

https://doi.org/10.1192/bjp.114.516.1325

Page 6/8 
Postnatal depression-NHS. (2018). Retrieved April 16, 2020, from https://www.nhs.uk/conditions/post-natal-depression/

Saligheh, M., Rooney, R. M., McNamara, B., \& Kane, R. T. (2014). The relationship between postnatal depression, sociodemographic factors, levels of partner support, and levels of physical activity. Frontiers in Psychology, 5(JUL), 597. https://doi.org/10.3389/fpsyg.2014.00597

Sempik, J; Aldridgem, J; Becker, S. (2003). Social and therapeutic horticulture: evidence and messages from research. Retrieved from https://repository.lboro.ac.uk/articles/Social_and_therapeutic_horticulture_the_state_of_practice_in_the_UK/9579860

Smith, M. V., Shao, L., Howell, H., Lin, H., \& Yonkers, K. A. (2011). Perinatal depression and birth outcomes in a Healthy Start project. Maternal and Child Health Journal, 15(3), 401-409. https://doi.org/10.1007/s10995-010-0595-6

Söderquist, J., Wijma, B., Thorbert, G., \& Wijma, K. (2009). Risk factors in pregnancy for post-traumatic stress and depression after childbirth. BJOG: An International Journal of Obstetrics \& Gynaecology, 116(5), 672-680. https://doi.org/10.1111/j.1471-0528.2008.02083.x

Tazaki, M; Nakane, Y. (1997). WHOQOL-26 information. Tokyo, Japan: Kaneko Shobou.

Teychenne, M., Ball, K., \& Salmon, J. (2008, May 1). Physical activity and likelihood of depression in adults: A review. Preventive Medicine, Vol. 46, pp. 397411. https://doi.org/10.1016/j.ypmed.2008.01.009

Unruh, A. M. (2004). The meaning of gardens and gardening in daily life: A comparison between gardeners with serious health problems and healthy participants. Acta Horticulturae, 639, 67-73. https://doi.org/10.17660/ActaHortic.2004.639.7

WaliczekT.M.MattsonR.H.ZajicekJ.M. (1996). Psychological benefits of community gardening. J. Environ. Hort.

Zaers, S., Waschke, M., \& Ehlert, U. (2008). Depressive symptoms and symptoms of post-traumatic stress disorder in women after childbirth. Journal of Psychosomatic Obstetrics and Gynecology, 29(1), 61-71. https://doi.org/10.1080/01674820701804324

\section{Tables}

Due to technical limitations, the tables are only available as a download in the supplemental files section.

\section{Figures}




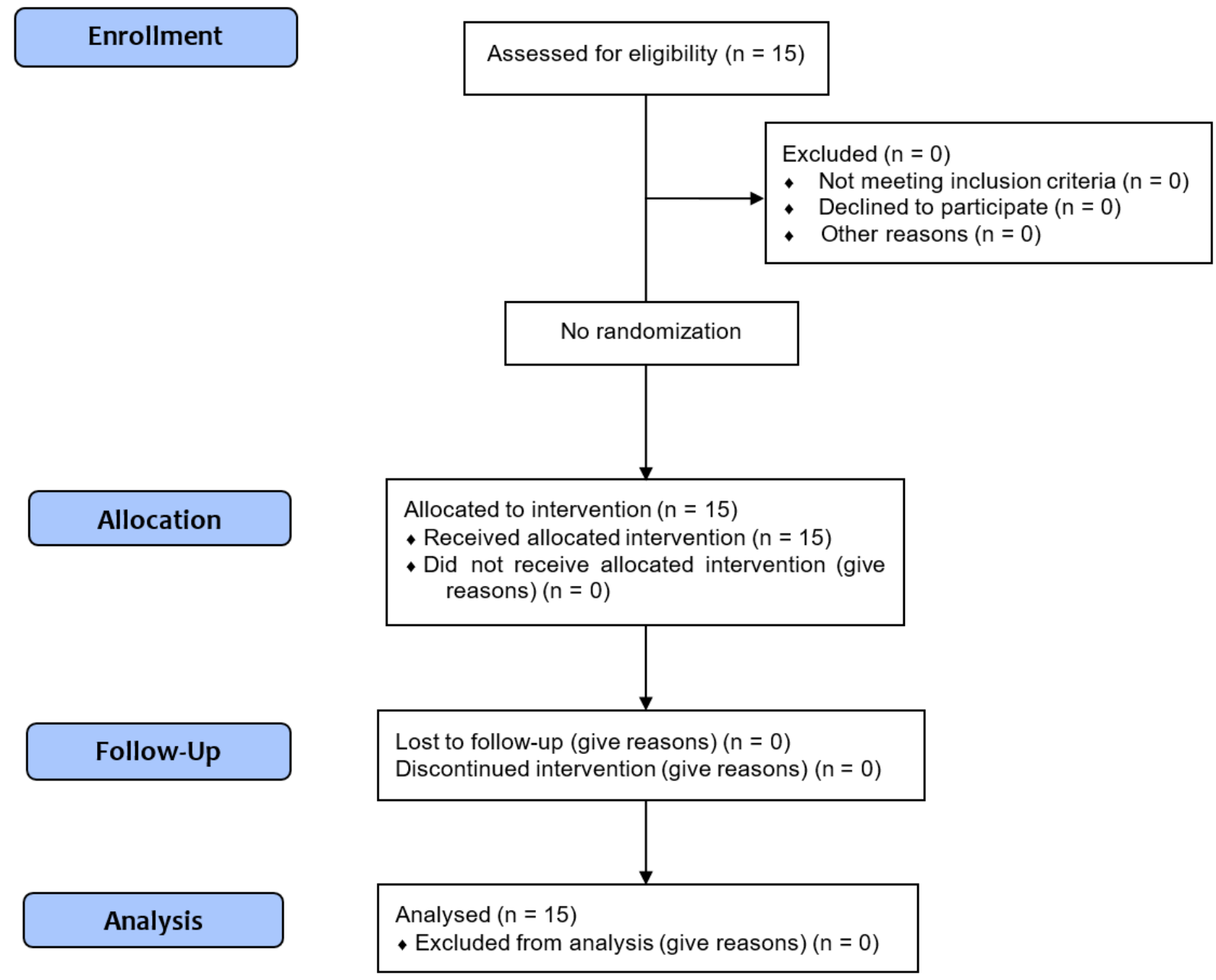

Figure 1

Consolidated standards of reporting trial (CONSORT) diagram

\section{Supplementary Files}

This is a list of supplementary files associated with this preprint. Click to download.

- HorticultureactivitiestoreducePSTableBMC.docx

- CONSORT2010Checklistkotoyuka.doc 